blood. When I saw the patient, so much excitement of the vascular and nervous systems had accumulated, that the worst was to be feared, unless the more available immediate means of relief were had recourse to, which were-firstly, the more obvious one of emptying the distended bladder, and secondly, the relief of the vascular system, by the more direct mode of depletion by venesection.

Another object fulfilled by the abstractions of blood, both the first and the second, besides that of securing the patient against an apprehended attack of puerperal convulsions, was that of guarding her against the inflammatory affections to which, as not uncommon results of protracted labours, she was liable to be exposed, and, perhaps, as curative of a state of inflammation already commenced. The successful treatment of the distended bladder by the use of the elastic catheter after the failure with the metallic instrument, is an important circumstance to be borne in mind by the student and junior practitioner.

The opiate exhibited after the labour was a full dose, and better calculated to procure rest, and subdue nervous irritation, than a smaller quantity; and the tartar emetic, probably, contributed in aid of the previous antiphlogistic treatment, to the prevention of reaction of the vascular system, and the early and prosperous recovery of the patient.

Russell-place, Fitzroy-square, June, 1845.

\section{ON POISONING BY OIL OF BITTER ALMONDS.}

\section{By H. LemheBx, M.B., Lecturer on Chemistry} at the London- Hospital.

E. W. M__ a boy, 13 years of age, the son of a bairdresser, was on Wednesday, June 25 th, left in charge of his father's shop. He was seen about half-past three o'clock in the afternoon, cheerful and well. Rather before four, his little sister, a child ten years old, found him lying on the floor. She ran to her father, who was down stairs, and told him that her brother was poisoned. When the father got to him, he was stretched along the floor upon his back. perfectly motionless and insensible; his face was deadly pale, the eyes open, and rolling from side to side, and he was panting for breath. His father raised him into the sitting posture, and then noticed that his limbs were quite supple, but powerless. In five minutes he was seen by $\mathrm{Mr}$ Henry, a surgeon of the Commercial-road, who found him still insensible, with his countenance placid, but very pale, the eyes half open, fixed, and the pupils dilated; reflex action had left, for the lid ceased to move when the eye was touched. He was breathing slowly, deeply, and at intervals of a minute or so. The pulse at the wrist was gone, though the heart was still beating with a feeble and tremulous effort. Knowing that the child was under the influence of oil of bitter almonds, he resorted to the usual remedies, dashing cold water upon his face and chest. $\mathrm{He}$ also tried to administer stimuli, but none could be got into the stomach. About four or five minutes after his arrival the child died, and it is presumed that this must have been about a quarter of an hour from the time of his swallowing the poison.

Post-mortem examination, twenty-four hours after death.-The face was still placid, but pale; the eyes half open; a little foam adhered to the mouth, and it had the smell of bitter almonds. The dependent parts of the body were livid; the lungs were congested, and the right side of the heart was gorged with dark fluid blood; the abdominal cavity gave out the odour of the poison, but this vas not noticed in any other part of the body; the stomach contained twelve ounces and a half of a palpy, semifluid matter, in process of digestion; it had a powerful odour of bitter almonds. The internal coat of the stomach was generally pale, but here and there, especially along the greater curvature, some red petechial patches were observed. On subjecting the fluid to distillation, and saturating with nitrate of silver, I procured one grain of cyanide of silver, indicating about two-tenths of a grain of pure hydrocyanic acid, a quantity contained in ten drops of the dilute acid of the Pharmacopoia; a further distillation enabled me to collect the volatile oil of the bitter almonds, freed, however, from prussic acid.

Remarks.-I learnt at the inquest, that the oil of bitter almonds which the father was in the habit of using, and which the children knew to be a poison, was kept in a cupboard of the room in which the child was found, but the bottle still stood in its place, and was tied over in the peculiar manner in which the father was accustomed to secure it. The cupboard was locked, and if the child had taken it of himself, he must have employed a chair to reach it, and yet there was no such thing near. Again, there was no vessel in the room out of which he could have drank it; his sister, however, suggested, on the day following, that he might have taken it from one of the bear's-grease pots, and on searching in a drawer of the shop, which a tjoined the room, they found one which still contained a little oil of bitter almonds. A difficulty now arose, whether the boy had taken it himself, or the little sister had given it to him. If he had taken it of himself, there could not have been time for him to have removed all the evidences of the act after he had swallowed the poison, and for him to have done this before, with the full consciousness of its being a poison, together with the fact that he had never exhibited the least indication of insanity, would have called for a verdict of "felo de se." Upon the other hand, if it had been administered by his little sister, of which there seemed some suspicion, she was exposed to a verdict of "wilful murder." These difficulties were felt by the coroner, and the verdict remained an open one.

The points of medical interest about it were, that the child was not convulsed, that he did not speak after he was seen, nor was there any scream or evacuation of the stomach, the bladder, or the rectum. He appeared to die from a paralysis of the respiratory muscles, the breathing becoming slower and slower.

From all the cases on record, it would appear that prussic acid killed by putting a stop to respiration and to the passage of the blood through the pulmonic capillaries. Now it seems to effect this in two, and those the most opposite, ways, either by producing a tetanic condition of the whole system, with spasm of the respiratory muscles, and this is the most common effect on animals, or else there is a perfect absence of convulsion, the limbs becoming powerless, and the muscles of respiration paralyzed. Opposite as these two conditions are, yet there are many cases which will illustrate both of them. Sarah Hart, Mrs. Belaney, the Jewess whose case I recorded in The Lancer for June 7, and many others, were violently convulsed. Again, in Mertzdorff's case of poisoning by oil of bitter almonds, * there were convulsions, and they were manifested also in that reported by $\mathbf{M}$. Chavasse, $f$ which is also interesting, because it shows the effects of prompt treatment. From his report it appears that a druggist swallowed oil of bitter almonds by mistake; his countenance immediately assumed the paleness of death; it became distorted; his eyes rolled about; his body was convulsed, and became deadly cold; he was delirious; his pulse was almost imperceptible, and he lay panting for breath; soon afterwards, vomiting supervened; and it was encouraged by sulphate of zinc. A prompt use of stimuli and warmth to the surface of his body rapidly restored him.

Upon the other hand, as I have said, paralysis may result from the action of this poison. One interesting case, which illustrates this, and shows the slow action of the poison, is recorded by Dr. Hayn.t His patient was an old hypochondriacal gentleman, who took about an ounce and a half of cherry laurel water, which he had kept by him for the purpose of committing suicide; no symptoms of cousequence appeared for about three hours, and then his feet and hands became paralyzed; his head also fell forwards on his chest, and he was quite unable to raise or support it; his mental faculties, however, were perfect to the last, and although his limbs were paralyzed, yet the function of sensation remained in them; in a few hours more the paralysis extended to the respiratory museles, his breathing became slower and slower until it ceased. Another case, also reported by Mr. Smith, in THE IAANCEx for June $8 \mathrm{th}, 1844$, illustrates the paralyzing influence of oil of bitter almonds. He says, "There was no spasm in either extremity; the limbs were completely lax, and fell lifeless when lifted." The brexthing also was slow and gentle. By the use of the cold-water douche, emetics, and stimuli, his patient recovered.

There does not appear to be any good reason why these opposite effects should be manifested, although I have before referred to the fact that any debilitating cause, such as fatigue, hunger, or disease, will not only render an animal more susceptible of the action of hydrocyanic acid, but that it then dies without any convulsions or scream. From the inquiries of the Florentine physicians, also, who have performed numerous experiments with the oil of bitter almonds, it appears that medium doses are those which most frequently occasion tetanus.

Those symptoms which appear to be most constant in the cases of poisoning by bitter almonds or cherry laurel, are a cadaverous or mortal paleness of the face and body, together with great coldness of the extremities; an almost im perceptible pulse, a slow or panting respiration, and, in the generality of cases, there are no convulsions, but a paralysis, first of the voluntary muscles, and then of the involuntary; after this a profound coma supervenes, and then death.

Upon a post-mortem examination, we find nearly the same appearances which hydrocyanic acid produces. The face and highest parts of the body are generally pale, the dependent livid; the countenance is generally placid, the eye, half-open, glassy, and prominent, the pupil dilated; foam may be adherent to the

* Archiv. fur Medizinische Erfahrung. 2, 1823.

† Journal de Chemie Médicale. Fev. 1840

+ Hufeland's "Journal der Praktischen Yeilkunde," Feb. 1843. 
mouth, and it will smell of the poison ; the lungs are greatly congested; the right side of the heart and the caræ gorged with black, nncoagulated blood; the cavities will generally have a strong odour of the bitter almond. The stomach may or may not be empty ; its contents will always, if recently opened, give out a powerful smell of the oil ; the inner coat is generally pale, excepting in one or two places, where there will be a blush of red, ( $I$ have seen this in three cases of poisoning by oil of bitter almonds,) and, altogether, there will be less doubt of the nature of the poison than in a case of poisoning by prussic acid, for a greater evidence will be furnished by the odour which is sure to be present in the stomach.

Tredegar-square, July 5 th, 1845.

\section{CLINICAL CONTRIBUTIONS FROM PRIVATE PRACTICE.}

FEVER, WITH ABSCESS OF THE SPLEEN.

Mr. Fergusson presents his compliments to the Editor of ThE LANCET, and begs to forward the enclosed, at the request of his old pupil and friend, Mr. Crrappins, the author of the paper. The preparation of the spleen has been sent to King's College, and Mr. Fergusson supposes it to be a rare specimen.

8, Dover-s'reet, June 16 th, 1845.

THE following case is remarkable, both for the rarity of its occurrence, and as a striking instance of the effects of purulent absorption in causing secondary deposits in different vital organs.

On Friday, the 26 th of $\mathrm{July}$, I was requested to see John A-aged fifteen, a lad of spare habit and sanguineous temperament, and a brickmaker by trade. On visiting him, I was informed that he had been ailing for about four days. He was sitting by the fire-side wrapped in blankets, and complained of intense cold, general lassitude, and debility, and of pains all over the body. His head was hot; the eyes were dull and suffused, and he complained more particalarly of a fixed pain in the left supra-orbital region. The respiration was natural, there was no pain on taking a deep inspiration, nor was there the least pain produced on firm pressure being made over any part of the abdomen. His shin was hot and dry, tongue furred, pulse 110 , full and strong; his general aspect indicated congestive fever. As this was the fourth day of his illness, as he complained a good deal of his head, and as reaction had already set in with some force, I felt reluctant to give him an emetic. He was, however, immediately bled, to the extent of about twenty ounces, in the erect posture, which produced complete syncope. He was ordered to be kept very clean and cool, to have his hair cut very short, and directed to take a mixture of Ejsom salts, tartar emetic, solution of acetate of ammonia, with sweet spirits of nitre and water, in divided doses, every two hours; he also got six gruins of calomel, and five of James's powder at bed-time; toast-water for drink.

On the 27 th, no diminution of fever whatever ; heat of head considerable; eyes suffused, with an intensely feverish look, and he still complained much of pain above the left eye; skin dry and parched ; tongue very much furred; pulse 116, firm and full; no pain whatever in any part of the abdomen on very firm pressure being made. His bowels had been very freely opened six or eight times, and the medicine had also acted upwards in a slight degree; the stools were bilious, and the secretion of urine tolerably free, considering the high degree of fever present. The blood taken the preceding day had, unfortunately, been thrown away by one of the attendants, so that I could not tell whether it was buffed. As his pulse, however, indicated it, I again bled him to the extent of about sixteen ounces, and ordered the same medicines to be continued, with the addition of four scruples of nitre to the saline mixture. I also ordered half a dozen leeches to be applied behind the ears, in consequence of his complaining so much about his head, and a cold lotion to the forehead.

28th.-The blood drawn the previous day was buffed and cupped, the leeches had taken a good deal of blood, the orifices having continued to discharge almost all night, and his head was entirely relieved. His bowels had been freely opened; he had no cough; the respiration was free and natural; the abdomen was soft, and I could not detect the slightest-trace of disease in that cavity. He had, however, a peculiarly dusky typhoid look about him; his skin was burning hot and dry, his pulse 114, and not at all changed in character; secretion of urine scanty and very high coloured. Finding that salines and the other remedies proved of no avail in arresting or mitigating the fever, and dreading the continuance of a highly congestive state of the system, Inow put him under a course of mercury. I directed a scruple of the chloride of mereury, eight grains of ipecacuanha, and a drachm of nitre, to be divided into eight powders; of these he was to take one every two hours. To have nothing but toast-water for drink; to have clean bed-linen, and plenty of fresh air.

Monday 29th.-He now, for the first time, complained of pain in the region of the spleen on firm pressure being made, but in no other part of the abdomen; pulse 118 , firm and full, skin hot and $d r y$, great thirst, bowels open, had slept little the preceding night. His intellect was clear, and there was an absence of all cephalic symptoms. His aspect was, however, more typhoid than ever; the powders were ordered to be continued, and twelve leeches were directed to be applied to the left hypochondrium, to be followed by the constant application of hot fomentations.

30th. - Though the oozing from the orifices made by the leeches continued all night, and though the fomentations had been applied incessantly, he still complained of great pain on pressure in the region of the spleen. Pulse 114, tongue furred, but not dry; heat of skin great. The powders were continued, and twelve more leeches were ordered to be applied as before, with hot fomentations, \&c.

Wednesday, 31st. - The same symptoms still persistent. The powders were continued, and ten leeches were applied as before.

Thursday, 1st August. There was little or no change in any of the symptoms. His pulse remained as full and firm as it had been, and he complained much of pain in the affected organ. A smart purgative draught was now administered, after the operation of which the mercurial powders were recommenced with.

Friday, 2nd.- On visiting him, I was informed that he had had a very severe rigor about four in the morning. His pulse was 120 , full and throbbing, notwithstanding that he had lost a good deal of blood, through the application of the leeches, during the two preceding days. His skin remained hot and dry, without the slightest tendency to perspiration, but his tongue still continued more or less moist. The purgative had operated freely, but still there was no mitigation whatever of the local pain. There was a dull apathetic look about him, and an indifference to all surrounding objects, which was very remarkable; still, as there was no marked disturbance of the nervous system, as his strength continued good, his pulse firm and full, indicating strong reaction of the vascular system, and as the type of fever was essentially inflammatory, I deemed it prudent, notwithstanding the accession of rigors, to continue the use of the preceding powders, only substituting James's powder for the nitre, in proportionate doses.

On Saturday morning he was attacked with rigors at the very same hour, followed by intense heat of skin, but no perspiration whatever. I saw him about nine in the morning; his pulse then ranged from 120 to 125 , and was firm and full, notwithstanding the recurrence of rigors only a few hours pieviously. His bowels had been opened; his tongue was disposed to becomedry; secretion of urine scanty; his respiration continued natural, but he could not take a deep inspiration without experiencing pain in the left hypochondrium, which was particularly tender on pressure. The powders were discontinued, as it was evident that suppuration had taken place. He was ordered a cup of beef-tea, and an anodyne draught was directed to be taken at night.

I visited him early on Sunday morning, and was told that he had another rigor, of great intensity, at the very same hour in the morning, from the effects of which he seemed scarcely to have rallied. His pulse was 140 , and so small and feeble as to be very easily extinguished; his aspect was collapsed; his tongue was dry and furred, with sordes abont the gums; the mouth was in an aphthous state; the pain in the left side continued unabated, and there was a degree of tension and tumefaction of the abdomen generally, indicating an inflammatory state of the peritoneum. The mercury had not produced the slightest effect upon the system, although he had taken upwards of 110 grains of calomel. He was now ordered a mixture of quinine, bark and acid, beeftea, port wine, \&c.

Monday, 5th. - Reaction had again taken place, for his pulse (130) was as full and bounding as ever; his tongue continued dry, and had a highly-glazed appearance, indicative of suppuration. He had experienced two more risors during the night; he also seemed to have a slight hacking cough, but he conld breathe freely and without pain. As he still complained bitterly of the pain, I ordered a hot turpentine epithem to be applied to the left hypochondrium. The bark mixture was continued, with strong beef-tea as before.

Tuesday and Wednesday.-The fever still continued unabated; pulse 140, full and voluminons as ever. His cough became very troublesome, the respiration hurried and laborious, with a degree of spasmodic action of the diaphrarm almost approaching to singultus; in fact, it was very evident that the diaphragm was 